\title{
Genetic alterations and epigenetic alterations of cancer-associated fibroblasts (Review)
}

\author{
HENG DU and GUOWEI CHE \\ Department of Thoracic Surgery, West China Hospital, Sichuan University, Chengdu, Sichuan 610041, P.R. China
}

Received April 10, 2015; Accepted July 12, 2016

DOI: $10.3892 / \mathrm{ol} .2016 .5451$

\begin{abstract}
Cancer-associated fibroblasts (CAFs) are one major type of component identified in the tumor microenvironment. Studies have focused on the genetic and epigenetic status of CAFs, since they are critical in tumor progression and differ phenotypically and functionally from normal fibroblasts. The present review summarizes the recent achievements in understanding the gene profiles of CAFs and pays special attention to their possible epigenetic alterations. A total of 7 possible genetic alterations and epigenetic changes in CAFs are discussed, including gene differential expression, karyotype analysis, gene copy number variation, loss of heterozygosis, allelic imbalance, microsatellite instability, post-transcriptional control and DNA methylation. These genetic and epigenetic characteristics are hypothesized to provide a deep understanding of CAFs and a perspective on their clinical significance.
\end{abstract}

\section{Contents}

1. Introduction

2. Differential expression of certain special genes in CAFs

3. Karyotype analysis in CAFs

4. DNA CNVs in CAFs

5. $\mathrm{LOH}$ and $\mathrm{AI}$

6. MSI

7. Epigenetic alterations

8. Clinical significance, controversies and future outlook

9. Conclusion

Correspondence to: Professor Guowei Che, Department of Thoracic Surgery, West China Hospital, Sichuan University, 37 Guoxue Lane, Wuhou, Chengdu, Sichuan 610041, P.R. China E-mail: hxcheguowei@yahoo.com

Key words: cancer-associated fibroblasts, genetic alteration, epigenetic changes, tumor microenvironment

\section{Introduction}

It is widely recognized that the accumulation of various harmful genetic alterations in normal cells may induce malignant cancer cells (1). Genetic mutation is one genetic alteration, but not all genetic mutations are harmful. Genetic mutation promotes biological evolution and results in biodiversity (2,3). Genetic alterations include genetic mutation, gene copy number variation $(\mathrm{CNV})$, loss of heterozygosity ( $\mathrm{LOH})$, allelic imbalance (AI) and microsatellite instability (MSI). Epigenetic alterations, represented by post-transcriptional control and DNA methylation, have been the focus of recent studies.

Cancer-associated fibroblasts (CAFs) are one major type of component in the tumor microenvironment (4). CAFs differ phenotypically and functionally from normal fibroblasts (NFs) (5). CAFs provide cancer cells with nutrition and promote the proliferation, invasion and metastasis of cells (6-9). CAFs maintain their phenotype for numerous passages during culture in vitro without exposure to cancer cells, while NFs cannot be infinitely proliferous like cancer cells (10). Therefore, it has been demonstrated that genetic or epigenetic alterations may be responsible for the special features of CAFs (Fig. 1) (10). Due to the critical role of CAFs during cancer progression, the genetic characterization of CAFs aids in the investigation of cancer therapy. The present review summarizes the current knowledge regarding 7 possible genetic and epigenetic alterations in CAFs.

\section{Differential expressions of certain special genes in CAFs}

CAFs are different from NFs, and their unique phenotypes and functions are partly determined by differences in gene expression. The differences between CAFs and NFs in gene expression have been extensively compared; in one study, 31 genes in breast CAFs, which were identified using Affymetrix Human Genome U133 Plus 2.0 and an empirical Bayesian model, were different from those in NFs (11). Of the 31 genes, the 21 upregulated genes were primarily associated with cell paracrine and intracellular signaling, transcription regulation and cell adhesion and migration, and their transcriptional products included transforming growth factor- $\beta 2$ (TGF- $\beta 2$ ), insulin-like growth factor-binding protein 2 and transcriptional factor AP- $2 \alpha / \gamma(11)$. By contrast, the 10 downregulated genes were primarily associated with epithelial membrane proteins (11). Genes mainly involved in coding adhesion molecules and growth factors have also been found 
to be upregulated in other types of CAFs, including colon (12) and pancreatic (13). The prostaglandin-endoperoxide synthase 2 gene (PTGS2), which encodes cyclooxygenase-2, was found to upregulate the expression of TGF- $\beta 2$ (14). These results are consistent with another study concerning the gene expression profiling of breast CAFs, which were detected using a complementary DNA microarray (15).

A study on the gene signature of CAFs in non-small cell lung cancer (NSCLC) revealed similar results to those observed in breast CAFs (16). In total, there were 46 genes differently expressed in CAFs compared with NFs, and the upregulated genes were enriched in cell signal transduction, cell adhesion, cell response to stress and angiogenesis (16). In total, of $6 / 46$ genes were also associated with the TGF- $\beta$ signaling pathway (16). TGF- $\beta$ is a multifunctional signaling factor(17-19), whichisinvolvedin the epithelial-to-mesenchymal transition (EMT) $(20,21)$. This may be one origin of CAFs (5). Cellular tumor antigen 53 (p53) signal transduction and genes associated with cell apoptosis and death were downregulated in colon CAFs (22). In addition, the gene expression profiling of CAFs may be prognostically significant for patients with NSCLC or colorectal cancer (CRC) $(16,22)$.

The differences in gene expression between CAFs and NFs are in keeping with the special function of CAFs in promoting cancer progression. CAFs promote the growth of cancer cells by providing nutrition to tumor cells $(23,24)$, and facilitate the invasion and metastasis of tumor cells by secreting matrix metalloprotease to resolve the matrix surrounding cancer cells (16,25-28). Additionally, CAFs activate tumor angiogenesis (29-31).

CAFs have a gene expression signature different from NFs, and upregulated genes are primarily associated with angiogenesis, EMT, cell adhesion and cell interactions $(32,33)$. The gene expression profiles of CAFs are different among various tumors, despite certain general features. In the 3 subtypes of breast tumor, which are differentiated according to 3 receptors, estrogen, human epidermal growth factor receptor 2 (HER2) and progesterone, the gene expression profiles of CAFs are even subtype-specific (34), which may be used to distinguish the 3 subtypes (32). Cancer stage also affects the gene expression profiling of CAFs in breast cancer (35).

\section{Karyotype analysis in CAFs}

A karyotype, which is defined as the chromosomal composition in an individual cell, reflects the number and structure of chromosomes. Humans are diploid with 46 chromosomes; however, cancer cells are usually polyploidy or aneuploidy with a larger nuclei-cytoplasm ratio compared with normal cells. Polyploidy helps cancer cells to resist adverse factors, and tetraploid cell lines are more viable than diploid cell lines (36). Whether or not CAFs have various chromosome karyotypes in a way that is similar to cancer cells remains controversial. No clear differences have been identified in the chromosome karyotype of CAFs in oral carcinoma (37). By contrast, CAFs from 2 types of tumors, namely melanoma and prostate cancer (xenograft or spontaneous), are characterized by aneuploid karyotypes, which are caused by the attenuated activation of p53 in CAFs (38). Common reasons that account for the conflicting results observed include the heterogeneity of CAFs and the various anatomical locations. Furthermore, the largest difference between the two aforementioned studies is the time in cell culturing; the study that identified positive karyotype alterations had cultured CAFs for $\geq 20$ weeks prior to testing (38). Since survival advantage in the tumor microenvironment, caused by selection pressures, is the reason for the alteration of karyotypes, a long-term culture is more likely to obtain CAFs with altered karyotypes.

Senescence that is activated by signals in CAFs, including growth-regulated oncogene- 1 and the TGF- $\beta$ /connective tissue growth factor pathway, may fuel and promote the growth of cancer cells $(39,40)$. Polyploidy is one of the three steps leading to the immortality of cancer cells, and cells with normal karyotypes cannot avoid senescence (41). Consequently, whether the absence of chromosome karyotype may cause CAF senescence and whether the senescent CAFs then promote tumor growth remains unclear.

\section{DNA CNVs in CAFs}

CNVs are particularly common in tumors and can contribute to tumor progression (42). The multiplex ligation-dependent probe amplification technique has previously demonstrated the presence of gene dosage alterations in ovarian cancer CAFs, and CNV was identified in $61 \%$ of genes (43). Amplifications and deletions were detected in CAFs in colorectal and breast carcinomas, and the presence of $17 \mathrm{CNVs}$ was confirmed by representational oligonucleotide microarray analysis (44). Ephrin type receptor (Eph) A4, EphA2 and EphB2 were also identified in these alterations, and EphA4 may be directly associated with tumor angiogenesis and progression; thus Ephs may be attractive drug targets for cancer therapy $(45,46)$. By contrast, CNVs were not identified in $95 \%$ of 98 patients, including 484 frozen specimens (47), and this study suggested that previous studies exhibiting a high frequency of CNVs are not entirely believable, since formalin-fixed and paraffin-embedded (FFPE) specimens have been used and, thus, the high number of CNVs may reflect an FFPE-related artifact. Finally, the authors of the aforementioned study concluded that the tumor microenvironment is genomically stable (47). The present authors hypothesize that genetic statuses are different among various types of tumor. However, $\mathrm{CNVs}$ in colorectal and breast carcinomas have been detected without using FFPE specimens (44). Thus, investigations using more specific and accurate methods are required.

\section{LOH and AI}

Numerous forms of genetic alterations, including MSI, LOH, $\mathrm{AI}$ and $\mathrm{CNV}$, have been observed in benign and malignant epithelial neoplasms. The $\mathrm{LOH}$-induced tumor suppressor gene (TSG) mutation is common among cancer epithelial cells (48-50). Whether or not $\mathrm{LOH}$ and AI are present in CAFs has been the focus of studies in recent years.

Several types of cancer, including head and neck squamous cell carcinoma (HNSCC), breast cancer, ovarian cancer, bladder cancer and CRC, and their associated stromata have been investigated since 2000. LOH or AI was revealed in all these cancer stromata. The $\mathrm{LOH}$ of the p53 and BRCA1 genes in chromosome 17 was identified in ulcerative colitis (UC)-associated 
carcinogenesis (51) and CRC (52). The LOH in stromal cells is associated with the colitis-associated carcinogenesis, and the frequency is increased compared with cancer cells (51). In CAFs of HNSCC, LOH is identified in the tumor protein 53 (TP53) and phosphatase and tensin homolog (PTEN) genes (two important tumor-suppressing genes) and the frequency is associated with tumor size and lymph node metastasis (53). $\mathrm{LOH}$ in TP53 is also observed in bladder cancer CAFs (54). The frequency of $\mathrm{LOH}$ in chromosome 3p21.3, a region that harbors 3 hyaluronidase genes potentially encoding the hyaluronidase tumor suppressor, in the stromal cells of ovarian cancer is similar to the frequency in cancer cells (55). However, LOH in these genes does not affect the accumulation of hyaluronidase or tumor progress (55). Breast cancer is most commonly used in the detection of $\mathrm{LOH}$ and $\mathrm{AI}$, and numerous studies focus on TP53 and PTEN (56). The LOHs of TP53 and PTEN have been identified in hereditary and sporadic breast cancers: Hereditary patients are more prone to TP53 mutation; however, it is only in sporadic breast cancer that LOHs of TP53 and PTEN are associated with cancer lymph node metastasis, tumor grade and type of estrogen receptor $(57,58)$. The frequency of $\mathrm{LOH}$ is high in sporadic breast cancer, and $\mathrm{LOH}$ at certain loci is noted only in stromal cells; these loci primarily code TSGs $(51,53)$. $\mathrm{LOH}$ and $\mathrm{AI}$ of certain genes occur in tumor and stromal cells, while some occur only in tumor or stromal cells $(53,56)$. The occurrence of $\mathrm{LOH}$ in the cancer epithelium or stromal cells is not completely random; certain unique loci may contain an increased frequency of LOH compared with other loci, whilst several loci may act as trigger points, at which a $\mathrm{LOH}$ may result in a $\mathrm{LOH}$ at another locus $(59,60)$. p53 mutations in CAFs also affect the CAF in question. $\mathrm{LOH}$ or complete loss of p53 in CAFs leads to the accumulation of stroma in cancer tissues, an increased proliferation of mesenchymal cells and a mesenchymal response (61). p53 status is involved in clinical treatment, since a LOH of p53 in CAFs weakens the response of cancer cells to radiotherapy and chemotherapy $(38,62)$. Recently, the acquired resistance to targeted chemotherapy of pulmonary adenocarcinoma, including epidermal growth factor receptor tyrosine kinase inhibitor (EGFR-TKI), has attracted more attention, and EMT may be one major reason $(63,64)$. Since EMT may be one origin of CAFs (5), the present study hypothesizes that the $\mathrm{p} 53$ status or $\mathrm{LOH}$ of p53 in CAFs of pulmonary adenocarcinoma may play a role in the resistance against EGFR-TKI. p53 status in cancer cells has been shown to be associated with tumor angiogenesis (65-68). Regarding the reason for the multifunctionality of CAFs, altered p53 signal transduction in CAFs may also be associated with angiogenesis.

Overall, the present review concludes that genetic alterations in cancer and stromal cells may occur independently, at least in breast cancer. In addition, interactions and cross-talk exist between tumor epithelia and supportive stromal cells. Stromal cells should be recognized as an equal and independent interactive component, rather than a response or an accessory to the carcinoma.

\section{MSI}

MSI represents a defective mismatch repair and is one feature of tumors (69). MSI occurs not only in cancer epithelial cells, but also in CAFs. MSI occurs in $41 \%$ of CRC CAFs vs. $34 \%$ of cancer cells (70). MSI in cancer cells is positively correlated with differentiation and Duke's stage; however, in CAFs, MSI is more frequent in samples with Duke's stage A (55\%) and well-differentiated CRCs (54\%) (70). In addition, MSI occurs in UC-associated CRC CAFs, since MSI in CAFs is associated with TSGs, including p53 (71). Furthermore, TSG instability is more important at the early stage of UC-associated oncogenesis (72). MSI also occurs at the early stage of esophageal cancer CAFs, but the frequency is increased in squamous cell carcinoma compared with in Barrett's adenocarcinoma (73).

With the exception of MSI in the nuclei of CAFs, MSI in DNA occurs in the cytoplasmic mitochondria (Mt) of CRC CAFs. The Mt genome contains 16,569 nucleotides that encode 2 ribosomal RNAs and 22 transfer RNAs, the production of which is critical for oxidative phosphorylation (74). MtMSI has already been reported in several types of cancer cells (75-77). MtMSI in CAFs is primarily detected in the D-loop of MtDNA, which contains transcription and replication regulatory elements (78). Different from nuclear MSI, MtMSI in CRC CAFs is not related to Duke's stage, or to nuclear MSI of CAFs or cancer cells. MtMSI may work only in the development, but not progression, of tumorigenesis (79).

\section{Epigenetic alterations}

Background. An epigenetic alteration is a local and global gene expression regulation, which is achieved primarily through DNA modification and nucleosome rearrangement rather than changes in DNA base pairs (80). The initiation and progression of cancer may be accompanied by genetic alterations and epigenetic regulations (81). Epigenetic alterations are divided into several subtypes, including post-transcriptional control, DNA (promoter) methylation, long-range epigenetic regulation, local nucleosome remodeling, deposition of histone proteins and covalent modification of canonical core histones (82). Certain subtypes associated with CAFs have already been confirmed.

Post-transcriptional control. Post-transcriptional control is a key process in gene expression, and its major tool is microRNA (miRNA). miRNAs are small non-coding RNAs of 19-25 nucleotides. miRNA is involved in numerous cellular progresses, including development, differentiation, cell response to stress, cell proliferation and apoptosis $(83,84)$. miRNA acts as an oncogene and tumor suppressor through various target genes (85). The functions of miRNA have been widely investigated in various types of cancer cells (86).

The most relevant studies focus on tumor microenvironment and miRNA in CAFs (Table I). Recent studies on breast cancer have revealed various miRNA statuses in CAFs. CAF cell lines from 6 patients and paired NFs have been analyzed using miRNA microarrays to identify 11 dysregulated miRNAs (87). In total, 3/11 miRNAs (miRs), including miR-221-5p, -221-3p and $-31-3 p$, were found to be upregulated, and the remaining 8 miRNAs, including miR-26b, -101, -141, -200b, -200c, -205 , $-342-3 p$ and $-\mathrm{let}-7 \mathrm{~g}$ were found to be downregulated (87). These 11 miRNAs target interleukin-6 (IL-6), TGF- $\beta$ and hepatocyte growth factor signaling pathways, which affect cell proliferation, differentiation, secretion, migration, intercellular adhesion 
Table I. miR status in cancer-associated fibroblasts of various cancer types.

\begin{tabular}{llll}
\hline Cancer type & \multicolumn{1}{c}{ miR profile } & Status & \\
\hline Breast & miR-221-5p, miRNA-221-3p, & Target genes \\
& miR-31-3p and miR-21 & $\uparrow$ & TGF- $\beta$, IL-6, HGF, ETS-2 and Ki-67 \\
& miR-26b, miR-101, miR-141, & $\downarrow$ & \\
miR-200b, miR-200c, miR-205, & & \\
Bladder & miR-342-3p, let-7g and miR-320 & & \\
& miR-16 and miR-320 & $\uparrow$ & TNF- $\alpha$, FGF-inducible4 and pro-angiogenic miR \\
Ovarian & miR-143 and miR-145 & $\downarrow$ & \\
& miR-155 & $\uparrow$ & CCL5 or other chemokines secreted by CAFs \\
Gastric & miR-31 and miR-214 & $\downarrow$ & \\
Endometrial & miR-148 & $\uparrow$ & TGF- $\beta$ /Smad \\
Prostate & miR-15 and miR-16 & $\downarrow$ & Wnt-1 and Wnt-10 \\
SCC & miR-21 & $\downarrow$ & Bcl-2, Wnt, Bmi-1, Ccne1, Ccnd1, VEGF and IL-6 \\
Colorectal & miR-21 & $\downarrow$ & TPM1, TPM3 and TGF- $\beta$ \\
NSCLC & miR-186 & $\uparrow$ & PDCD4, SPRY1, SPRY2, NFI-B, RECK and PTEN \\
\hline
\end{tabular}

SCC, squamous cell carcinoma; NSCLC, non small cell lung cancer; miR, microRNA; $\uparrow$, upregulated; $\downarrow$, downregulated.

and interaction with other compartments in tumors (87). miR-320 and -21 are also different, since miR-320 is regulated by PTEN and its target gene is ETS proto-oncogene 2 (ETS2). The downregulation of miR-320 with the upregulation of ETS2 in PTEN-knocked-out CAFs promotes angiogenesis and cancer cell invasion (87). The PTEN-miR-320-ETS2 complex, which distinguishes between normal and tumor stroma, is associated with the recurrence of breast cancer (88). miR-21 in CAFs is associated with $\mathrm{Ki}-67$, and its high expression results in the increased proliferation of tumor cells $(89,90)$. The roles of miR-21 are different among various CAFs. In stage II CRC, CAFs with a high expression of miR-21 predicts poor disease-free survival (91). During the process between precancerous adenoma and advanced CRC, the frequency and extent of miR-21 expression are increased (91). In esophageal squamous cell carcinoma, miR-21 in CAFs affects the migration and invasion of cancer cells and may be involved in the activation of NFs to CAFs through tropomyosin (TPM) 1, TPM3 and TGF- $\beta$ pathways $(18,20,92)$.

Two other studies looking at CAFs in endometrial cancer have identified 12 miRNAs with various expressions (87). Among 12 miRNAs analyzed, miR-31 is the most downregulated (93), the target of which is the SATB2 homeobox gene. Special AT-rich sequence-binding protein 2 (SATB2) is a matrix attachment region-binding protein that codes cell type-specific transcriptional factor involved in regulating transcription in large chromatin domains (93). The upregulated expression of SATB2 in breast cancer is associated with increased tumor grade (94). SATB2 is highly expressed in breast cancer CAFs, which results in the increased capacity for promoting the migration of cancer cells and invasion of CAFs (93). The introduction of SATB2 into NFs could stimulate the expression of genes involved in the scattering, migration and invasion of cells (95). miR-148a is another reduced miRNA in breast cancer, and by acting with its target Wnt family member 10B (WNT10B), miR-148a promotes the migration of cancer cells without affecting growth rate (96). WNT10B may also be involved in the activation of CAFs (97).

miRNAs are also detected in other types of CAFs. Of the 4 miRNAs investigated in bladder cancer CAFs, 2 miRNAs (miR-16 and -320) are upregulated and 2 miRNAs are downregulated (98). Certain studies suggested that miR-16 may pro-apoptotically act as a tumor suppressor and miR-320 may be associated with DNA promoter methylation in cancer cells $(99,100)$. On the contrary, the expression of miR-143 and miR-145 is reduced in CAFs, and both are involved in tumor suppression (101). Ovarian CAFs contain 2 downregulated miRNAs (miR-31 and -214) and 1 upregulated miRNA (miR-155) compared with NFs. Mimicking the miRNA status using miRNA suppressors and transforming miRNAs could induce functional conversions from NFs to CAFs, while the reverse experiment can result in the conversion from CAFs to NFs (102). Notably, the upregulation of miR-214 is directly associated with chemokine (C-C motif) ligand 5, a chemokine that is abundant in the serum and promotes the invasion and migration of cancer stem cells, and these actions are similar to CAFs in ovarian cancer (103). However, miR-143 expression is upregulated in the CAFs of scirrhous gastric cancer rather than in the non-scirrhous types 40 (104). miR-143 enhances the expression of collagen type III through activating the TGF- $\beta /$ SMAD pathway 40 (104). The increased expression of miR-143 is associated with poor cancer-specific mortality, thus miR-143 may act as an independent prognostic factor (104). Two miRNAs (miR-15 and -16) with lower expressions have been indicated in the CAFs of prostate cancer, and the downregulation of each reduces the post-transcriptional repression of fibroblast growth factor-2/fibroblast growth factor receptor-1, which in turn promotes the growth and progression of cancer cells (105) Therefore, the decreased expressions of miR-15 and -16 also promote the growth of cancer cells. Oncogenes, such as $\mathrm{B}$ cell lymphoma 2 and Wnt, and angiogenesis-related genes 


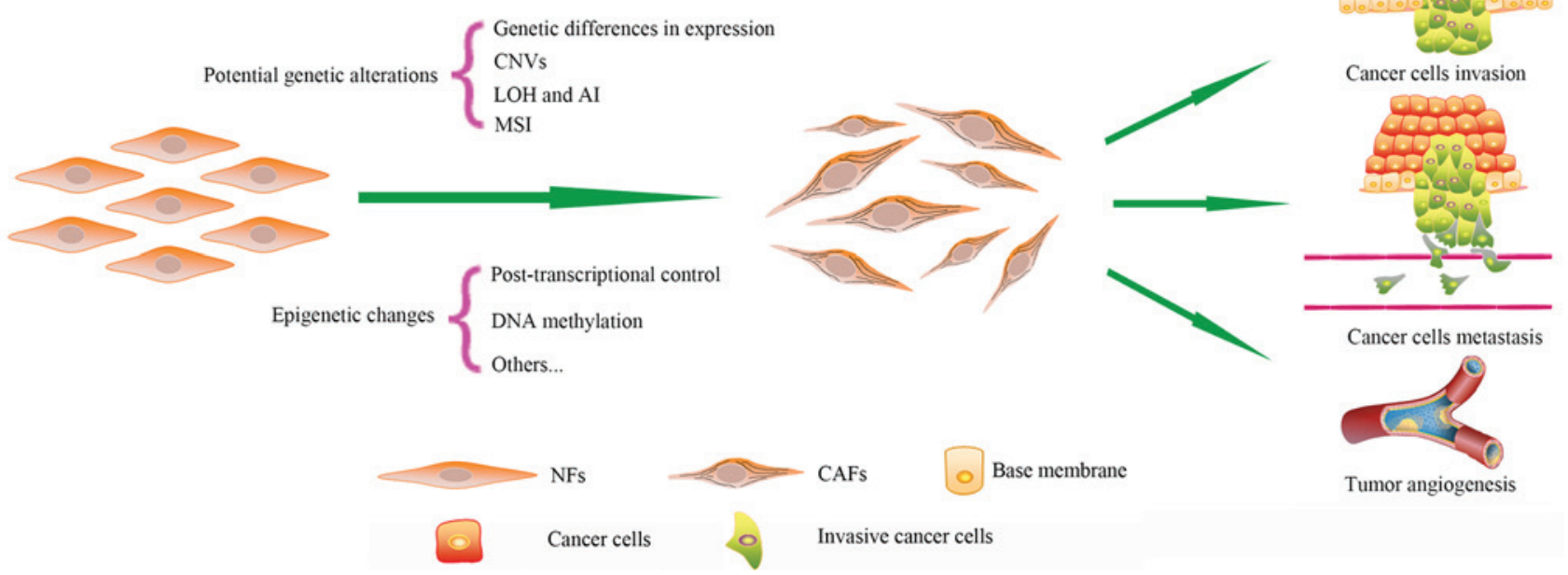

Figure 1. Genetic alterations and epigenetic changes in CAFs. Compared to NFs, CAFs possess numerous types of potential genetic alterations and epigenetic changes. These differences cause CAFs to differ phenotypically and functionally from NFs. Finally, CAFs promote cancer progression and act in cancer cell drug resistance. NFs, normal fibroblasts; CAFs, cancer-associated fibroblasts; CNVs, copy number variations; LOH, loss of heterozygosity; AI, allelic imbalance; MSI, microsatellite instability.

such as vascular endothelial growth factor and IL-6 (29), are involved in the target genes of these two miRNAs (105).

miR-186 in CAFs is involved in glycolysis, and combined with the 3'-untranslated region of its target gene glucose transporter 1 (Glut 1), it is active in regulating the uptake of glucose and production of lactate (106). The roles of CAFs in cancer glucose and energy metabolism are recognized using a novel method named the 'reverse Warburg effect' $(23,107,108)$. Caveolin-1 is a key pathway in the CAF metabolism conversion $(109,110)$. Whether or not miR-186 and Glut 1 are associated with the caveolin-1 pathway requires further research.

DNA methylation. DNA methylation is one epigenetic change and is mainly divided into two subtypes, hypermethylation and hypomethylation (80). DNA promoter hypermethylation could result in the silence of TSGs, while hypomethylation of oncogenes causes its activation or overexpression $(111,112)$. Thus, the two subtypes are critical for tumorigenesis. DNA methylation in CAFs has been widely investigated.

Tumor stroma is important for cancer progression. In $\mathrm{CRC}$, the components rich in connective tissues were found to have an accumulation of chondroitin sulphate proteoglycan. The relevant gene coding this proteoglycan contains a 3-fold decrease of hypomethylation and this change only occurs in the CAFs of tumor stroma, rather than in cancer cells $(113,114)$. The same hypomethylation is absent in the stroma of UC, indicating that chronic inflammation is not powerful enough to change cytosine methylation (115).

In prostate cancer, promoter hypermethylation of cyclin-dependent kinase inhibitor 2A, hypermethylated in cancer 1 protein, tumor suppressor candidate 3 and glutathione S-transferase P1 (GSTP1) is extremely abundant in cancer epithelial cells and CAFs (116). The GSTP1 promoter is methylated in $>90 \%$ of prostate cancers. Though GSTP1 may not suppress cancer cell growth and is not considered to be a TSG, it may be a caretaker gene and its aberrant silencing in CAFs may create a tumorigenic microenvironment (117). Promoter hypermethylation could also be responsible for the inactivation of another candidate TSG, the opioid binding protein/cell adhesion molecule-like gene, in invasive cervical cancer CAFs (118). In addition to hypermethylation, DNA promoter hypomethylation may also exist in CAFs. Activation of long interspersed nucleotide element-1 in tumorigenesis-related CRC is due to its hypomethylated promoter (119). Gene methylation profiles are associated with the status of receptors. In HER2/neu-positive breast cancer CAFs, 3 corresponding genes, including progesterone receptor, type IV 17- $\beta$-hydroxysteroid dehydrogenase and H-cadherin, are downregulated (120). These genes are methylated in breast cancer, but are only slightly or not methylated in non-neoplastic breast cancers (120). Gene methylation is a dynamic process in esophageal squamous cancer and cervical cancer; thus, the level of methylation changes with the progression of cancer $(121,122)$. Apart from locally methylated DNA, global gene hypomethylation was confirmed in CAFs of gastric cancer (123). Most importantly, global methylation of CAFs occurs as early as the dysplastic stage, which could potentially provide a novel strategy for early diagnosis.

Mechanistically, several possible reasons may explain the aberrant methylation in CAFs. The field effect could be a cause of methylation in certain CAFs, as this effect induces the spread of methylation among various types of cells $(124,125)$; for example, Septin 9 gene hypermethylation in CAFs occurs later than in CRC epithelial cells, which may reflect the spread of Septin 9 hypermethylation from CRC epithelial cells to CAFs. CAF methylation possibly occurs through field effects from cancer cells (126). In addition, abnormal cell proliferation, a local decrease of methyl donors under certain premalignant conditions, or both of these factors may result in hypomethylation $(123,126)$. As for DNA promoter hypermethylation in cancer cells, 3 possible mechanisms have been put forward, including the infidelity of maintenance DNA (cytosine-5)-methyltransferase (DNMT)1, the de novo methylating enzymes, DNMT3a and DNMT3b, and the faulty repair mechanism of aberrantly methylated DNA (127). Whether or 
not these 3 mechanisms are accurate and suitable for CAFs should be validated through additional studies.

\section{Clinical significance, controversies and future outlook}

Perspective on the clinical significance. Clinical trials have already used miRNAs as drug targets or biomarkers for the stratification of patients, prognosis and drug efficacy (128). miR-21 is upregulated in the CAFs of several cancer types and is selected as a diagnostic and prognostic marker. mir-21 is associated with the Duke's stage of CRC. Highly expressed stromal miR-21 predicts a poor recurrence-free survival (129). Combined with other miRNAs, plasma miR-21 could be a novel method for early cancer diagnosis. However, miR-143 usually shows a decreased expression and is considered as a cancer suppressor $(104,130,131)$. Erb-b2 receptor tyrosine kinase 3 (ERBB3), one of the four members of the ERBB family of receptor tyrosine kinases, is targeted by miR-143, which in turn prevents breast cancer cells from proliferation and invasion. EGFR-TKI drugs have a special effect in targeting cancer cells, but patients have to endure drug-resistance for several months after administration of the drugs. miR-143 could potentially be a novel pathway for targeted drugs as it can inhibit cancer cell invasion through an EGFR signalling pathway $(132,133)$. With regard to upregulated miR-221, a drug called 2'-O-methylphosphorothioate-modified anti-miRNA-221 has already demonstrated an antitumor effect in mouse models (134). The in vivo administration of tumor suppressor microRNA or inhibitors of tumor-promoting microRNA that target CAFs may be an emerging tumor treatment; this may be more effective compared with existing techniques, considering that CAFs have a relatively steady phenotype compared with cancer cells (134).

DNA methyltransferase inhibitors and DNA methyltransferase maybe be useful for combating CAFs possessing the corresponding hypermethylation and hypomethylation. The drugs, 5-azacytidine and 5-aza-2'-deoxycytidine, which have already been used for treatment of acute and chronic myeloid leukemia and myelodysplastic syndrome, have been investigated in the treatment other tumors; however, they are less effective in the treatment of solid tumors and have associated side effects (135).

Controversies and further outlook. Whether or not CAFs have somatic or genetic alterations remains controversial, despite certain alterations that have already been found. Studies that found a positive somatic alteration in CAFs, without exception, have extracted DNA from archival tissues. In other studies $(10,47,136,137)$, CAFs were isolated from fresh frozen tissues or flow cytometry; no somatic genetic alterations were found, while CAFs from FFPE show a high frequency of $\mathrm{LOH}$ and AI. This pattern indicates that FFPE tissues could result in highly fragmented DNA and RNA molecules, which are not suitable for large-scale genetic analysis. PCR amplification then exacerbates the artificial false positive result (138-143). Thus, certain studies refute genetic alterations and instead attribute the results to epigenetic alterations More reliable and accurate methods should be found to solve these controversies.

CAFs retain diploid rather than polyploid cancer cells, which may account for the senescence of CAFs. Since telomerase is closely linked with cell senescence, particularly in cancer cells, the activity and status of telomerase in CAFs may be worth additional studies, though certain studies have already been performed (144-146).

\section{Conclusion}

CAFs, which are phenotypically and functionally different from NFs due to numerous potential genetic alterations and epigenetic changes, are critical for tumor progression and have attracted increasing numbers of studies in recent years (Fig. 1). With the potential genetic and epigenetic alterations changes found in CAFs, the underlying mechanisms regarding the features of CAFs are gradually revealed. With the exception of genetic and epigenetic alterations, other relevant changes may also explain the differential expressions of genes in CAFs, and certain special genetic or epigenetic alterations may be confirmed in the future. Further investigation into the detailed genetic and epigenetic alterations of CAFs in the tumor microenvironment increases the understanding of CAFs and provides novel approaches for clinical application.

\section{Acknowledgements}

The present study was supported by the National Natural Science Foundation of China, Beijing, China (grant no. 81071929), which awarded the grant to Professor Guowei Che.

\section{References}

1. Lengauer C, Kinzler KW and Vogelstein B: Genetic instabilities in human cancers. Nature 396: 643-649, 1998.

2. Crispo E, Moore JS, Lee-Yaw JA, Gray SM and Haller BC: Broken barriers: Human-induced changes to gene flow and introgression in animals: An examination of the ways in which humans increase genetic exchange among populations and species and the consequences for biodiversity. Bioessays 33: 508-518, 2011.

3. Verde C, di Prisco G and Convey P: Molecular and genetic advances to understanding evolution and biodiversity in the polar regions. Mar Genomics 8: 1-2, 2012.

4. Jia CC, Wang TT, Liu W, Fu BS, Hua X, Wang GY, Li TJ, Li X, Wu XY, Tai Y, et al: Cancer-associated fibroblasts from hepatocellular carcinoma promote malignant cell proliferation by HGF secretion. PLoS One 8: e63243, 2013.

5. Xing F, Saidou J and Watabe K: Cancer associated fibroblasts (CAFs) in tumor microenvironment. Front Biosci (Landmark Ed) 15: 166-179, 2010.

6. Franco OE, Shaw AK, Strand DW and Hayward SW: Cancer associated fibroblasts in cancer pathogenesis. Semin Cell Dev Biol 21: 33-39, 2010.

7. Castello-Cros R, Bonnuccelli G, Molchansky A, Capozza F, Witkiewicz AK, Birbe RC, Howell A, Pestell RG, Whitaker-Menezes D, Sotgia F and Lisanti MP: Matrix remodeling stimulates stromal autophagy, 'fueling' cancer cell mitochondrial metabolism and metastasis. Cell Cycle 10: 2021-2034, 2011.

8. Balliet RM, Capparelli C, Guido C, Pestell TG, Martinez-Outschoorn UE, Lin Z, Whitaker-Menezes D, Chiavarina B, Pestell RG, Howell A, et al: Mitochondrial oxidative stress in cancer-associated fibroblasts drives lactate production, promoting breast cancer tumor growth: Understanding the aging and cancer connection. Cell Cycle 10: 4065-4073, 2011.

9. Bonuccelli G, Tsirigos A, Whitaker-Menezes D, Pavlides S, Pestell RG, Chiavarina B, Frank PG, Flomenberg N, Howell A, Martinez-Outschoorn UE, et al: Ketones and lactate 'fuel' tumor growth and metastasis: Evidence that epithelial cancer cells use oxidative mitochondrial metabolism. Cell Cycle 9: 3506-3514, 2010 
10. Qiu W,Hu M, Sridhar A, Opeskin K, Fox S, Shipitsin M, Trivett M, Thompson ER, Ramakrishna M, Gorringe KL, et al: No evidence of clonal somatic genetic alterations in cancer-associated fibroblasts from human breast and ovarian carcinomas. Nat Genet 40 650-655, 2008.

11. Bauer M, Su G, Casper C, He R, Rehrauer W and Friedl A: Heterogeneity of gene expression in stromal fibroblasts of human breast carcinomas and normal breast. Oncogene 29: $1732-1740,2010$

12. Nakagawa H, Liyanarachchi S, Davuluri RV, Auer H, Martin EW Jr, de la Chapelle A and Frankel WL: Role of cancer-associated stromal fibroblasts in metastatic colon cancer to the liver and their expression profiles. Oncogene 23 : 7366-7377, 2004.

13. Sato N, Maehara N and Goggins M: Gene expression profiling of tumor-stromal interactions between pancreatic cancer cells and stromal fibroblasts. Cancer Res 64: 6950-6956, 2004.

14. Yamada C, Aikawa T, Okuno E, Miyagawa K, Amano K, Takahata S, Kimata M, Okura M, Iida S and Kogo M: TGF- $\beta$ in jaw tumor fluids induces RANKL expression in stromal fibroblasts. Int J Oncol 49: 499-508, 2016.

15. Singer CF, Gschwantler-Kaulich D, Fink-Retter A, Haas C, Hudelist G, Czerwenka K and Kubista E: Differential gene expression profile in breast cancer-derived stromal fibroblasts Breast Cancer Res Treat 110: 273-281, 2008.

16. Navab R, Strumpf D, Bandarchi B, Zhu CQ, Pintilie M, Ramnarine VR, Ibrahimov E, Radulovich N, Leung L, Barczyk M, et al: Prognostic gene-expression signature of carcinoma-associated fibroblasts in non-small cell lung cancer. Proc Natl Acad Sci USA 108: 7160-7165, 2011

17. Grivennikov SI, Greten FR and Karin M: Immunity, inflammation and cancer. Cell 140: 883-899, 2010.

18. Derynck R, Akhurst RJ and Balmain A: TGF-beta signaling in tumor suppression and cancer progression. Nat Genet 29: $117-129,2001$.

19. Wakefield LM and Roberts AB: TGF-beta signaling: Positive and negative effects on tumorigenesis. Curr Opin Genet Dev 12: 22-29, 2002.

20. Zavadil J and Böttinger EP: TGF-beta and epithelial-to-mesenchymal transitions. Oncogene 24: 5764-5774, 2005.

21. Katsuno Y, Lamouille $S$ and Derynck R: TGF- $\beta$ signaling and epithelial-mesenchymal transition in cancer progression. Curr Opin Oncol 25: 76-84, 2013.

22. Herrera M, Islam AB, Herrera A, Martín P, García V, Silva J Garcia JM, Salas C, Casal I, de Herreros AG, et al: Functional heterogeneity of cancer-associated fibroblasts from human colon tumors shows specific prognostic gene expression signature. Clin Cancer Res 19: 5914-5926, 2013

23. Migneco G, Whitaker-Menezes D, Chiavarina B, Castello-Cros R, Pavlides S, Pestell RG, Fatatis A, Flomenberg N, Tsirigos A, Howell A, et al: Glycolytic cancer associated fibroblasts promote breast cancer tumor growth, without a measurable increase in angiogenesis: Evidence for stromal-epithelial metabolic coupling. Cell Cycle 9: 2412-2422, 2010.

24. Leiherer A, Geiger K, Muendlein A and Drexel H: Hypoxia induces a HIF-1 $\alpha$ dependent signalling cascade to make a complex metabolic switch in SGBS-adipocytes. Mol Cell Endocrinol 383: 21-31, 2014.

25. Hu C, Wang Z, Zhai L, Yang M, Shan L, Chai C, Liu M and Wang L: Effects of cancer-associated fibroblasts on the migration and invasion abilities of SGC-7901 gastric cancer cells. Oncol Lett 5: 609-612, 2013

26. Kim SH, Choe C, Shin YS, Jeon MJ, Choi SJ, Lee J, Bae GY, Cha HJ and Kim J: Human lung cancer-associated fibroblasts enhance motility of non-small cell lung cancer cells in co-culture. Anticancer Res 33: 2001-2009, 2013.

27. Cao M, Seike M, Soeno C, Mizutani H, Kitamura K, Minegishi Y, Noro R, Yoshimura A, Cai L and Gemma A: MiR-23a regulates TGF- $\beta$-induced epithelial-mesenchymal transition by targeting E-cadherin in lung cancer cells. Int J Oncol 41: 869-875, 2012

28. Schveigert D, Cicenas S, Bruzas S, Samalavicius NE, Gudleviciene Z and Didziapetriene J: The value of MMP-9 for breast and non-small cell lung cancer patients' survival. Adv Med Sci 58: 73-82, 2013

29. Nagasaki T, Hara M, Nakanishi H, Takahashi H, Sato M and Takeyama H: Interleukin- 6 released by colon cancer-associated fibroblasts is critical for tumour angiogenesis: Anti-interleukin-6 receptor antibody suppressed angiogenesis and inhibited tumour-stroma interaction. Br J Cancer 110: $469-478,2014$
30. Al-Ansari MM, Hendrayani SF, Tulbah A, Al-Tweigeri T, Shehata AI and Aboussekhra A: P16INK4A represses breast stromal fibroblasts migration/invasion and their VEGF-A-dependent promotion of angiogenesis through Akt inhibition. Neoplasia 14: 1269-1277, 2012

31. Orimo A, GuptaPB, Sgroi DC,Arenzana-Seisdedos F, Delaunay T, Naeem R, Carey VJ, Richardson AL and Weinberg RA: Stromal fibroblasts present in invasive human breast carcinomas promote tumor growth and angiogenesis through elevated SDF-1/CXCL12 secretion. Cell 121: 335-348, 2005.

32. Finak G, Bertos N, Pepin F, Sadekova S, Souleimanova M, Zhao H, Chen H, Omeroglu G, Meterissian S, Omeroglu A, et al: Stromal gene expression predicts clinical outcome in breast cancer. Nat Med 14: 518-527, 2008

33. Sadlonova A, Bowe DB, Novak Z, Mukherjee S, Duncan VE, Page GP and Frost AR: Identification of molecular distinctions between normal breast-associated fibroblasts and breast cancer-associated fibroblasts. Cancer Microenviron 2: 9-21, 2009 .

34. Tchou J, Kossenkov AV, Chang L, Satija C, Herlyn M, Showe LC and Puré E: Human breast cancer associated fibroblasts exhibit subtype specific gene expression profiles. BMC Med Genomics 5: 39, 2012.

35. Ma XJ, Dahiya S, Richardson E, Erlander M and Sgroi DC: Gene expression profiling of the tumor microenvironment during breast cancer progression. Breast Cancer Res 11: R7, 2009.

36. Park SU, Choi ES, Jang YS, Hong SH, Kim IH and Chang DK: Effects of chromosomal polyploidy on survival of colon cancer cells. Korean J Gastroenterol 57: 150-157, 2011 (In Korean).

37. Zheng XH, Liu Y, Zhou HM, Chen QM and Li BQ: Analysis of chromosome karyotype of oral carcinoma-associated Fibroblasts. Hua Xi Kou Qiang Yi Xue Za Zhi 23: 159-160, 2005 (In Chinese)

38. Dudley AC, Shih SC, Cliffe AR, Hida K and Klagsbrun M: Attenuated p53 activation in tumour-associated stromal cells accompanies decreased sensitivity to etoposide and vincristine. Br J Cancer 99: 118-125, 2008.

39. Yang G, Rosen DG, Zhang Z, Bast RC Jr, Mills GB, Colacino JA, Mercado-Uribe I and Liu J: The chemokine growth-regulated oncogene 1 (Gro-1) links RAS signaling to the senescence of stromal fibroblasts and ovarian tumorigenesis. Proc Natl Acad Sci USA 103: 16472-16477, 2006.

40. CapparelliC, Whitaker-Menezes D, Guido C,BallietR,Pestell TG, Howell A, Sneddon S, Pestell RG, Martinez-Outschoorn U, Lisanti MP and Sotgia F: CTGF drives autophagy, glycolysis and senescence in cancer-associated fibroblasts via HIF1 activation, metabolically promoting tumor growth. Cell Cycle 11: 2272-2284, 2012

41. Erenpreisa $\mathbf{J}$ and Cragg MS: Three steps to the immortality of cancer cells: Senescence, polyploidy and self-renewal. Cancer Cell Int 13: 92, 2013.

42. Bowcock AM: Invited review DNA copy number changes as diagnostic tools for lung cancer. Thorax 69: 495-496, 2014.

43. Tuhkanen H, Anttila M, Kosma VM, Heinonen S, Juhola M, Helisalmi S, Kataja V and Mannermaa A: Frequent gene dosage alterations in stromal cells of epithelial ovarian carcinomas. Int J Cancer 119: 1345-1353, 2006.

44. Pelham RJ, Rodgers L, Hall I, Lucito R, Nguyen KC, Navin N, Hicks J, Mu D, Powers S, Wigler M and Botstein D: Identification of alterations in DNA copy number in host stromal cells during tumor progression. Proc Natl Acad Sci USA 103: 19848-19853, 2006.

45. Carles-Kinch K, Kilpatrick KE, Stewart JC and Kinch MS: Antibody targeting of the EphA2 tyrosine kinase inhibits malignant cell behavior. Cancer Res 62: 2840-2847, 2002

46. Mao W, Luis E, Ross S, Silva J, Tan C, Crowley C, Chui C, Franz G, Senter P, Koeppen H and Polakis P: EphB2 as a therapeutic antibody drug target for the treatment of colorectal cancer. Cancer Res 64: 781-788, 2004.

47. Rummel S, Valente AL, Kane JL, Shriver CD and Ellsworth RE: Genomic (in)stability of the breast tumor microenvironment. Mol Cancer Res 10: 1526-1531, 2012.

48. Rohrbach H, Haas CJ, Baretton GB, Hirschmann A, Diebold J, Behrendt RP and Löhrs U: Microsatellite instability and loss of heterozygosity in prostatic carcinomas: Comparison of primary tumors and of corresponding recurrences after androgen-deprivation therapy and lymph-node metastases. Prostate 40: 20-27, 1999.

49. Smith HS, Lu Y, Deng G, Martinez O, Krams S, Ljung BM, Thor A and Lagios M: Molecular aspects of early stages of breast cancer progression. J Cell Biochem Suppl 17G: 144-152, 1993. 
50. Agapova LS, Ivanov AV, Sablina AA, Kopnin PB, Sokova OI Chumakov PM and Kopnin BP: P53-dependent effects of RAS oncogene on chromosome stability and cell cycle checkpoints. Oncogene 18: 3135-3142, 1999.

51. Matsumoto N, Yoshida T and Okayasu I: High epithelial and stromal genetic instability of chromosome 17 in ulcerative colitis-associated carcinogenesis. Cancer Res 63: 6158-6161, 2003

52. Wernert N, Löcherbach C, Wellmann A, Behrens P and Hügel A Presence of genetic alterations in microdissected stroma of human colon and breast cancers. Anticancer Res 21: 2259-2264, 2001.

53. Moinfar F, Man YG, Arnould L, Bratthauer GL, Ratschek M and Tavassoli FA: Concurrent and independent genetic alterations in the stromal and epithelial cells of mammary carcinoma: Implications for tumorigenesis. Cancer Res 60 : 2562-2566, 2000.

54. Paterson RF, Ulbright TM, MacLennan GT, Zhang S, Pan CX Sweeney CJ, Moore CR, Foster RS, Koch MO, Eble JN and Cheng L: Molecular genetic alterations in the laser-capture-microdissected stroma adjacent to bladder carcinoma. Cancer 98: 1830-1836, 2003.

55. Tuhkanen H, Anttila M, Kosma VM, Ylä-Herttuala S, Heinonen S, Kuronen A, Juhola M, Tammi R, Tammi M and Mannermaa A: Genetic alterations in the peritumoral stromal cells of malignant and borderline epithelial ovarian tumors as indicated by allelic imbalance on chromosome 3p. Int J Cancer 109: 247-252, 2004.

56. Kurose K, Gilley K, Matsumoto S, Watson PH, Zhou XP and Eng C: Frequent somatic mutations in PTEN and TP53 are mutually exclusive in the stroma of breast carcinomas. Nat Genet 32: 355-357, 2002.

57. Patocs A, Zhang L, Xu Y, Weber F, Caldes T, Mutter GL, Platzer P and Eng C: Breast-cancer stromal cells with TP53 mutations and nodal metastases. N Engl J Med 357: 2543-2551, 2007.

58. Fukino K, Shen L, Patocs A, Mutter GL and Eng C: Genomic instability within tumor stroma and clinicopathological characteristics of sporadic primary invasive breast carcinoma. JAMA 297: 2103-2111, 2007.

59. Fukino K, Shen L, Matsumoto S, Morrison CD, Mutter GL and Eng C: Combined total genome loss of heterozygosity scan of breast cancer stroma and epithelium reveals multiplicity of stromal targets. Cancer Res 64: 7231-7236, 2004.

60. Kurose K, Hoshaw-Woodard S, Adeyinka A, Lemeshow S, Watson PH and Eng C: Genetic model of multi-step breast carcinogenesis involving the epithelium and stroma: Clues to tumour-microenvironment interactions. Hum Mol Genet 10 1907-1913, 2001.

61. Hill R, Song Y, Cardiff RD and Van Dyke T: Selective evolution of stromal mesenchyme with p53 loss in response to epithelial tumorigenesis. Cell 123: 1001-1011, 2005.

62. Hawsawi NM, Ghebeh H, Hendrayani SF, Tulbah A, Al-Eid M, Al-Tweigeri T, Ajarim D, Alaiya A, Dermime S and Aboussekhra A: Breast carcinoma-associated fibroblasts and their counterparts display neoplastic-specific changes. Cancer Res 68: 2717-2725, 2008

63. Chung JH, Rho JK, Xu X, Lee JS, Yoon HI, Lee CT, Choi YJ, Kim HR, Kim CH and Lee JC: Clinical and molecular evidences of epithelial to mesenchymal transition in acquired resistance to EGFR-TKIs. Lung Cancer 73: 176-182, 2011

64. Shang Y, Cai X and Fan D: Roles of epithelial-mesenchymal transition in cancer drug resistance. Curr Cancer Drug Targets 13: 915-929, 2013.

65. Schmid JO, Dong M, Haubeiss S, Friedel G, Bode S, Grabner A, Ott G, Mürdter TE, Oren M, Aulitzky WE and van der Kuip H: Cancer cells cue the p 53 response of cancer-associated fibroblasts to cisplatin. Cancer Res 72: 5824-5832, 2012.

66. Assadian S, El-Assaad W, Wang XQ, Gannon PO, Barrès V, Latour M, Mes-Masson AM, Saad F, Sado Y, Dostie J and Teodoro JG: P53 inhibits angiogenesis by inducing the production of Arresten. Cancer Res 72: 1270-1279, 2012.

67. Farhang Ghahremani M, Goossens S, Nittner D, Bisteau X, Bartunkova S, Zwolinska A, Hulpiau P, Haigh K, Haenebalcke L, Drogat $\mathrm{B}$, et al: $\mathrm{P} 53$ promotes VEGF expression and angiogenesis in the absence of an intact p21-Rb pathway. Cell Death Differ 20 888-897, 2013

68. Teodoro JG, Parker AE, Zhu X and Green MR: P53-mediated inhibition of angiogenesis through up-regulation of a collagen prolyl hydroxylase. Science 313: 968-971, 2006.

69. Heinimann K: Toward a molecular classification of colorectal cancer: The role of microsatellite instability status. Front Oncol 3: 272, 2013.
70. Matsumoto N, Yoshida T, Yamashita K, Numata Y and Okayasu I: Possible alternative carcinogenesis pathway featuring microsatellite instability in colorectal cancer stroma. Br J Cancer 89: 707-712, 2003

71. Yagishita H, Yoshida T, Ishiguro K, Numata Y and Okayasu I Epithelial and stromal genetic instability linked to tumor suppressor genes in ulcerative colitis-associated tumorigenesis. Scand J Gastroenterol 43: 559-566, 2008.

72. Liu X, Goldblum JR, Zhao Z, Landau M, Heald B, Pai R and Lin J: Distinct clinicohistologic features of inflammatory bowel disease-associated colorectal adenocarcinoma: in comparison with sporadic microsatellite-stable and Lynch syndrome-related colorectal adenocarcinoma. Am J Surg Pathol 36: 1228-1233, 2012.

73. Shiraishi H, Mikami T, Yoshida T, Tanabe S, Kobayashi N, Watanabe $M$ and Okayasu I: Early genetic instability of both epithelial and stromal cells in esophageal squamous cell carcinomas, contrasted with Barrett's adenocarcinomas. J Gastroenterol 41: 1186-1196, 2006.

74. Chomyn A and Attardi G: MtDNA mutations in aging and apoptosis. Biochem Biophys Res Commun 304: 519-529, 2003

75. Liu VW, Shi HH, Cheung AN, Chiu PM, Leung TW, Nagley P, Wong LC and Ngan HY: High incidence of somatic mitochondrial DNA mutations in human ovarian carcinomas. Cancer Res 61: 5998-6001, 2001.

76. Habano W, Sugai T, Nakamura SI, Uesugi N, Yoshida T and Sasou S: Microsatellite instability and mutation of mitochondrial and nuclear DNA in gastric carcinoma. Gastroenterology 118: 835-841, 2000.

77. Habano W, Nakamura S and Sugai T: Microsatellite instability in the mitochondrial DNA of colorectal carcinomas: Evidence for mismatch repair systems in mitochondrial genome. Oncogene 17: 1931-1937, 1998.

78. Suzuki M, Toyooka S, Miyajima K, Iizasa T, Fujisawa T, Bekele NB and Gazdar AF: Alterations in the mitochondrial displacement loop in lung cancers. Clin Cancer Res 9: 5636-5641, 2003

79. Kim HS, Lim HS, Lee SH, Lee JW, Nam SW, Park WS, Lee YS, Lee JY and Yoo NJ: Mitochondrial microsatellite instability of colorectal cancer stroma. Int J Cancer 119: 2607-2611, 2006.

80. Dey P: Epigenetic changes in tumor microenvironment. Indian J Cancer 48: 507-512, 2011.

81. Ting AH, McGarvey KM and Baylin SB: The cancer epigenome-components and functional correlates. Genes Dev 20: 3215-3231, 2006

82. Lund AH and van Lohuizen M: Epigenetics and cancer. Genes Dev 18: 2315-2335, 2004

83. Ambros V: The functions of animal microRNAs. Nature 431: 350-355, 2004

84. Bartel DP: MicroRNAs: Genomics, biogenesis, mechanism and function. Cell 116: 281-297, 2004.

85. Chen CZ: MicroRNAs as oncogenes and tumor suppressors. N Engl J Med 353: 1768-1771, 2005.

86. Di Leva G and Croce CM: Roles of small RNAs in tumor formation. Trends Mol Med 16: 257-267, 2010.

87. Zhao L, Sun Y, Hou Y, Peng Q, Wang L, Luo H, Tang X, Zeng Z and Liu M: MiRNA expression analysis of cancer-associated fibroblasts and normal fibroblasts in breast cancer. Int J Biochem Cell Biol 44: 2051-2059, 2012.

88. Bronisz A, Godlewski J, Wallace JA, Merchant AS, Nowicki MO, Mathsyaraja H, Srinivasan R, Trimboli AJ, Martin CK, Li F, et al: Reprogramming of the tumour microenvironment by stromal PTEN-regulated miR-320. Nat Cell Biol 14: 159-167, 2011.

89. Rask L, Balslev E, Jørgensen S, Eriksen J, Flyger H, Møller S, Høgdall E, Litman T and Nielsen BS: High expression of miR-21 in tumor stroma correlates with increased cancer cell proliferation in human breast cancer. APMIS 119: 663-673, 2011.

90. Pathmanathan N and Balleine RL: Ki67 and proliferation in breast cancer. J Clin Pathol 66: 512-516, 2013.

91. Yamamichi N, Shimomura R, Inada K, Sakurai K, Haraguchi T, Ozaki Y, Fujita S, Mizutani T, Furukawa C, Fujishiro M, et al: Locked nucleic acid in situ hybridization analysis of miR-21 expression during colorectal cancer development. Clin Cancer Res 15: 4009-4016, 2009

92. Nouraee N, Roosbroeck K, Vasei M, Semnani S, Samaei NM, Naghshvar F, Omidi AA, Calin GA and Mowla SJ: Expression, tissue distribution and function of miR-21 in esophageal squamous cell carcinoma. PLoS One 8: e73009, 2013.

93. Dobreva G, Dambacher J and Grosschedl R: SUMO modification of a novel MAR-binding protein, SATB2, modulates immunoglobulin mu gene expression. Genes Dev 17: 3048-3061, 2003. 
94.Patani N, Jiang W, Mansel R, Newbold R and Mokbel K: The mRNA expression of SATB1 and SATB2 in human breast cancer. Cancer Cell Int 9: 18, 2009.

95. Aprelikova O, Yu X, Palla J, Wei BR, John S, Yi M, Stephens R, Simpson RM, Risinger JI, Jazaeri A and Niederhuber J: The role of miR-31 and its target gene SATB2 in cancer-associated fibroblasts. Cell Cycle 9: 4387-4398, 2010.

96. Aprelikova O, Palla J, Hibler B, Yu X, Greer YE, Yi M, Stephens R, Maxwell GL, Jazaeri A, Risinger JI, et al: Silencing of miR-148a in cancer-associated fibroblasts results in WNT10B-mediated stimulation of tumor cell motility. Oncogene 32: 3246-3253, 2013.

97. Wei J, Melichian D, Komura K, Hinchcliff M, Lam AP, Lafyatis R, Gottardi CJ, MacDougald OA and Varga J: Canonical Wnt signaling induces skin fibrosis and subcutaneous lipoatrophy: A novel mouse model for scleroderma? Arthritis Rheum 63: 1707-1717, 2011.

98.Enkelmann A, Heinzelmann J, von Eggeling F, Walter M, Berndt A, Wunderlich $\mathrm{H}$ and Junker K: Specific protein and miRNA patterns characterise tumour-associated fibroblasts in bladder cancer. J Cancer Res Clin Oncol 137: 751-759, 2011.

99.Schepeler T, Reinert JT, Ostenfeld MS, Christensen LL, Silahtaroglu AN, Dyrskjøt L, Wiuf C, Sørensen FJ, Kruhøffer M, Laurberg S, et al: Diagnostic and prognostic microRNAs in stage II colon cancer. Cancer Res 68 : 6416-6424, 2008.

100. Lee KH, Lotterman C, Karikari C, Omura N, Feldmann G, Habbe N, Goggins MG, Mendell JT and Maitra A: Epigenetic silencing of MicroRNA miR-107 regulates cyclin-dependent kinase 6 expression in pancreatic cancer. Pancreatology 9 293-301, 2009.

101. Wang X, Tang S, Le SY, Lu R, Rader JS, Meyers C and Zheng ZM: Aberrant expression of oncogenic and tumor-suppressive microRNAs in cervical cancer is required for cancer cell growth. PLoS One 3: e2557, 2008.

102.Mitra AK, Zillhardt M, Hua Y, Tiwari P, Murmann AE, Peter ME and Lengyel E: MicroR NAs reprogram normal fibroblasts into cancer-associated fibroblasts in ovarian cancer. Cancer Discov 2: 1100-1108, 2012

103.Long H, Xie R, Xiang T, Zhao Z, Lin S, Liang Z, Chen Z and Zhu B: Autocrine CCL5 signaling promotes invasion and migration of CD133+ovarian cancer stem-like cells via NF-кB-mediated MMP-9 upregulation. Stem Cells 30: 2309-2319, 2012

104.Naito Y, Sakamoto N, Oue N, Yashiro M, Sentani K, Yanagihara K, Hirakawa K and Yasui W: MicroRNA-143 regulates collagen type III expression in stromal fibroblasts of scirrhous type gastric cancer. Cancer Sci 105: 228-235, 2014.

105. Musumeci M, Coppola V, Addario A, Patrizii M Maugeri-Saccà M, Memeo L, Colarossi C, Francescangeli F, Biffoni M, Collura D, et al: Control of tumor and microenvironment cross-talk by miR-15a and miR-16 in prostate cancer. Oncogene 30: 4231-4242, 2011.

106. Sun P, Hu JW, Xiong WJ and Mi J: MiR-186 regulates glycolysis through Glut1 during the formation of cancer-associated fibroblasts. Asian Pac J Cancer Prev 15: 4245-4250, 2014.

107.Pavlides S, Whitaker-Menezes D, Castello-Cros R, Flomenberg N, Witkiewicz AK, Frank PG, Casimiro MC, Wang C, Fortina P, Addya S, et al: The reverse Warburg effect: Aerobic glycolysis in cancer associated fibroblasts and the tumor stroma. Cell Cycle 8: 3984-4001, 2009.

108.Sotgia F, Martinez-Outschoorn UE, Pavlides S, Howell A, Pestell RG and Lisanti MP: Understanding the Warburg effect and the prognostic value of stromal caveolin-1 as a marker of a lethal tumor microenvironment. Breast Cancer Res 13: 213, 2011.

109.Sotgia F, Martinez-Outschoorn UE, Howell A, Pestell RG, Pavlides S and Lisanti MP: Caveolin-1 and cancer metabolism in the tumor microenvironment: Markers, models, and mechanisms. Annu Rev Pathol 7: 423-467, 2012.

110. Razani B, Zhang XL, Bitzer M, von Gersdorff G, Böttinger EP and Lisanti MP: Caveolin-1 regulates transforming growth factor (TGF)-beta/SMAD signaling through an interaction with the TGF-beta type I receptor. J Biol Chem 276: 6727-6738, 2001.

111. Jones PA and Baylin SB: The fundamental role of epigenetic events in cancer. Nat Rev Genet 3: 415-428, 2002.

112. Wilson AS, Power BE and Molloy PL: DNA hypomethylation and human diseases. Biochim Biophys Acta 1775: 138-162, 2007.
113. Adany R, Heimer R, Caterson B, Sorrell JM and Iozzo RV Altered expression of chondroitin sulfate proteoglycan in the stroma of human colon carcinoma. Hypomethylation of PG-40 gene correlates with increased PG-40 content and mRNA levels. J Biol Chem 265: 11389-11396, 1990.

114. Adany R and Iozzo RV: Altered methylation of versican proteoglycan gene in human colon carcinoma. Biochem Biophys Res Commun 171: 1402-1413, 1990.

115. Adany R and Iozzo RV: Hypomethylation of the decorin proteoglycan gene in human colon cancer. Biochem J 276 301-306, 1991.

116. Kekeeva TV, Popova OP, Shegă PV, Alekseev BIa, Adnreeva IuIu,Zaletaev DV and Nemtsova MV: Abberant methylation of p16, HIC1, N33 and GSTP1 genes in tumor epitelium and tumor-associated stromal cells of prostate cancer. Mol Biol (Mosk) 41: 79-85, 2007 (In Russian).

117. Rodriguez-Canales J, Hanson JC, Tangrea MA, Erickson HS, Albert PS, Wallis BS, Richardson AM, Pinto PA, Linehan WM, Gillespie JW, et al: Identification of a unique epigenetic sub-microenvironment in prostate cancer. J Pathol 211: 410-419, 2007.

118. Ye F, Zhang SF, Xie X and Lu WG: OPCML gene promoter methylation and gene expression in tumor and stroma cells of invasive cervical carcinoma. Cancer Invest 26: 569-574, 2008.

119. Matsunoki A, Kawakami K, Kotake M, Kaneko M, Kitamura H, Ooi A, Watanabe G and Minamoto T: LINE-1 methylation shows little intra-patient heterogeneity in primary and synchronous metastatic colorectal cancer. BMC Cancer 12: 574, 2012.

120. FieglH,Millinger S, Goebel G, Müller-Holzner E, Marth C, Laird PW and Widschwendter M: Breast cancer DNA methylation profiles in cancer cells and tumor stroma: Association with HER-2/neu status in primary breast cancer. Cancer Res 66: 29-33, 2006.

121. Dawsey SP, Roth MJ, Adams L, Hu N, Wang QH, Taylor PR and Woodson K: COX-2 (PTGS2) gene methylation in epithelial, subepithelial lymphocyte and stromal tissue compartments in a spectrum of esophageal squamous neoplasia. Cancer Detect Prev 32: 135-139, 2008

122. Zhuang J, Jones A, Lee SH, Ng E, Fiegl H, Zikan M, Cibula D, Sargent A, Salvesen HB, Jacobs IJ, et al: The dynamics and prognostic potential of DNA methylation changes at stem cell gene loci in women's cancer. PLoS Genet 8: e1002517, 2012

123. Jiang L, Gonda TA, Gamble MV, Salas M, Seshan V, Tu S, Twaddell WS, Hegyi P, Lazar G, Steele I, et al: Global hypomethylation of genomic DNA in cancer-associated myofibroblasts. Cancer Res 68: 9900-9908, 2008.

124. Wasserkort R, Kalmar A, Valcz G, Spisak S, Krispin M, Toth K, Tulassay Z, Sledziewski AZ and Molnar B: Aberrant septin 9 DNA methylation in colorectal cancer is restricted to a single CpG island. BMC Cancer 13: 398, 2013.

125. Hanson JA, Gillespie JW, Grover A, Tangrea MA, Chuaqui RF, Emmert-Buck MR, Tangrea JA, Libutti SK, Linehan WM and Woodson KG: Gene promoter methylation in prostate tumor-associated stromal cells. J Natl Cancer Inst 98: 255-261, 2006

126. Kim YI, Fawaz K, Knox T, Lee YM, Norton R, Arora S, Paiva L and Mason JB: Colonic mucosal concentrations of folate correlate well with blood measurements of folate status in persons with colorectal polyps. Am J Clin Nutr 68: 866-872, 1998.

127. Momparler RL: Cancer epigenetics. Oncogene 22: 6479-6483, 2003.

128. Hayes J, Peruzzi PP and Lawler S: MicroRNAs in cancer: Biomarkers, functions and therapy. Trends Mol Med 20: 460-469, 2014

129. Nielsen BS, Jørgensen S, Fog JU, Søkilde R, Christensen IJ, Hansen U, Brünner N, Baker A, Møller S and Nielsen HJ: High levels of microRNA-21 in the stroma of colorectal cancers predict short disease-free survival in stage II colon cancer patients. Clin Exp Metastasis 28: 27-38, 2011.

130.Dou L, Zheng D, Li J, Li Y, Gao L, Wang L and Yu L: Methylation-mediated repression of microRNA-143 enhances MLL-AF4 oncogene expression. Oncogene 31: 507-517, 2012

131.Liu R, Liao J, Yang M, Sheng J, Yang H, Wang Y, Pan E, Guo W, $\mathrm{Pu}$ Y, Kim SJ and Yin L: The cluster of miR-143 and miR-145 affects the risk for esophageal squamous cell carcinoma through co-regulating fascin homolog 1. PLoS One 7: e33987, 2013.

132. Zhu H, Dougherty U, Robinson V, Mustafi R, Pekow J, Kupfer S, Li YC, Hart J, Goss K, Fichera A, et al: EGFR signals downregulate tumor suppressors miR-143 and miR-145 in Western diet-promoted murine colon cancer: role of G1 regulators. Mol Cancer Res 9: 960-975, 2011. 
133. Wang Q, Cai J, Wang J, Xiong C and Zhao J: MiR-143 inhibits EGFR-signaling-dependent osteosarcoma invasion. Tumour Biol 35: 12743-12748, 2014.

134.Wang X, Baumgartner C, Shields DC, Deng HW and Beckmann JS (eds): Application of Clinical Bioinformatics. Springer Netherlands, pp126, 2016.

135. Anestopoulos I, Voulgaridou GP, Georgakilas AG, Franco R, Pappa A and Panayiotidis MI: Epigenetic therapy as a novel approach in hepatocellular carcinoma. Pharmacol Ther 145: 103-119, 2015

136. Corver WE, Ter Haar NT, Fleuren GJ and Oosting J: Cervical carcinoma-associated fibroblasts are DNA diploid and do not show evidence for somatic genetic alterations. Cell Oncol (Dordr) 34: 553-563, 2011

137. Walter K, Omura N, Hong SM, Griffith M and Goggins M: Pancreatic cancer associated fibroblasts display normal allelotypes. Cancer Biol Ther 7: 882-888, 2008.

138. Erez N, Truitt M, Olson P, Arron ST and Hanahan D Cancer-associated fibroblasts are activated in incipient neoplasia to orchestrate tumor-promoting inflammation in an NF-kappaB-dependent manner. Cancer Cell 17: 135-147, 2010.

139. Martinez-Outschoorn UE, Whitaker-Menezes D, Lin Z, Flomenberg N, Howell A, Pestell RG, Lisanti MP and Sotgia F: Cytokine production and inflammation drive autophagy in the tumor microenvironment: Role of stromal caveolin-1 as a key regulator. Cell Cycle 10: 1784-1793, 2011.
140. Servais C and Erez N: From sentinel cells to inflammatory culprits: Cancer-associated fibroblasts in tumour-related inflammation. J Pathol 229: 198-207, 2013.

141. Shiels MS, Engels EA, Shi J, Landi MT, Albanes D, Chatterjee N, Chanock SJ, Caporaso NE and Chaturvedi AK: Genetic variation in innate immunity and inflammation pathways associated with lung cancer risk. Cancer 118: 5630-5636, 2012.

142. Pavlides S, Tsirigos A, Vera I, Flomenberg N, Frank PG, Casimiro MC, Wang C, Fortina P, Addya S, Pestell RG, et al: Loss of stromal caveolin-1 leads to oxidative stress, mimics hypoxia and drives inflammation in the tumor microenvironment, conferring the 'reverse Warburg effect' a transcriptional informatics analysis with validation. Cell Cycle 9: 2201-2219, 2010

143. Lehmann U and Kreipe H: Real-time PCR analysis of DNA and RNA extracted from formalin-fixed and paraffin-embedded biopsies. Methods 25: 409-418, 2001.

144. Ale-Agha N, Dyballa-Rukes N, Jakob S, Altschmied J and Haendeler J: Cellular functions of the dual-targeted catalytic subunit of telomerase, telomerase reverse transcriptase-potential role in senescence and aging. Exp Gerontol 56: 189-193, 2014.

145. Urquidi V, Tarin D and Goodison S: Role of telomerase in cell senescence and oncogenesis. Annu Rev Med 51: 65-79, 2000.

146. Shawi M and Autexier C: Telomerase, senescence and ageing. Mech Ageing Dev 129: 3-10, 2008. 